Portland State University

PDXScholar

6-16-2021

\title{
Relationships Between Coping Mechanisms and Perceived Stress of Portland State University Community Members Amidst COVID-19
}

Julie Goldman

Portland State University

Follow this and additional works at: https://pdxscholar.library.pdx.edu/honorstheses

Part of the Mental and Social Health Commons, and the Public Health Commons Let us know how access to this document benefits you.

Recommended Citation

Goldman, Julie, "Relationships Between Coping Mechanisms and Perceived Stress of Portland State University Community Members Amidst COVID-19" (2021). University Honors Theses. Paper 1100. https://doi.org/10.15760/honors.1127

This Thesis is brought to you for free and open access. It has been accepted for inclusion in University Honors Theses by an authorized administrator of PDXScholar. Please contact us if we can make this document more accessible: pdxscholar@pdx.edu. 


\title{
Relationships Between Coping Mechanisms and Perceived Stress of Portland State
} University Community Members Amidst COVID-19

\author{
by \\ Julie Goldman \\ An undergraduate honors thesis submitted in partial fulfillment of the \\ requirements for the degree of \\ Bachelor of Science \\ in \\ University Honors \\ and \\ Public Health Studies: Pre-Clinical Health Science
}

Thesis Adviser

Claire Wheeler MD, Ph.D

Portland State University 


\begin{abstract}
Purpose: The purpose of this study was to assess the coping mechanisms used by the Portland State University (PSU) community and their relationships to perceived stress.

Methods: A virtual survey composed of demographic questions, the Perceived Stress Scale (PSS10), the Brief COPE, and two open-ended questions was distributed to the community. Data were collected from 231 respondents, mostly PSU students. Statistical Package for the Social Sciences (SPSS) was used to compute mean PSS score, adaptive coping score, and avoidant coping score. Pearson correlations and t-tests were run to explore the relationship between perceived stress and coping data.

Results: Perceived stress of the study population was higher than normative college student values. Greater use of adaptive coping mechanisms than avoidant coping mechanisms were reported by participants. A positive correlation between the use of avoidant coping and perceived stress was found, while adaptive coping and perceived stress were found to have a negative correlation. While female respondents were found to have higher perceived stress levels than males, gender was not found to be a moderator in the relationship between stress and coping. Specific coping mechanisms were reported by participants to be effective for them including physical activity and social support. The COVID-19 pandemic increased the stress of many of the respondents.
\end{abstract}

Conclusions: Mind-body practices and physical activity may act as adaptive coping mechanisms that can aid in decreasing perceived stress. These strategies should be encouraged on college campuses especially considering the detrimental effects the pandemic has had on mental health and wellbeing.

Keywords: perceived stress, coping, student, PSS10, Brief COPE, COVID-19 


\section{Relationships Between Coping Mechanisms and Perceived Stress of Portland State University Community Members Amidst COVID-19}

\section{Background}

The adverse effects of stress on health are well documented, as are multiple ways of coping that can reduce or worsen the impact of stress on a person's life. Stress is a physiological state that arises as a result of a person's cognitive response to a stressor (Sapolsky, 1994). When the stressor is perceived to be threatening to one's wellbeing, the individual then needs to evaluate whether they are able to cope with said stressor. Based on that evaluation, a coping behavior is selected. While some may think of coping as adaptive behaviors only, by definition, coping is any behavior a person engages in as a response to a stressful situation (APA, 2020). Over time the effect of coping behaviors has an impact on one's overall wellbeing, a multifactorial state that allows an individual to fully engage in and find satisfaction in life, in many dimensions including physical, emotional, spiritual, intellectual, social, occupational, financial, and environmental (CDC, 2018).

The physical body reacts to stress by activating the hypothalamic-pituitary-adrenal axis (HPA axis) and the sympathetic-adrenal-medullary axis (SAM axis) which produce neuroendocrine hormones such as cortisol and catecholamines (Padgett \& Glaser, 2003). When these pathways are activated as a result of acute stress, the secretion of stress hormones is a healthy response that allows the immediate threat to be addressed. Chronic activation of these pathways as a result of chronic stress leads to increased secretion of stress hormones. This increase results in suppression of the adaptive immune system response, with a corresponding enhancement of innate immunity and inflammation. As such, chronic activation of the physiological stress response may lead to increased vulnerability to infectious disease and inflammation-driven chronic disease. 
Sheldon Cohen began exploring the concept of "perceived stress" almost 40 years ago and became a pioneer of this growing field (Cohen et al., 1983). Perceived stress arises in response to the objective challenge of life events and the individual's perception of those events. In 1983, Cohen et al. created the Perceived Stress Scale (PSS), a series of questions designed to measure the feelings and thoughts one has around stressful situations in their life over the past month. The PSS is still the most extensively used psychological measurement of perceived stress (Cohen, 1994).

People may respond differently to stress and therefore have varied ranges of coping abilities. "Coping strategies protect both mental and physical health from the negative effects of stress" (Furman et al., 2018, 61). The Brief COPE questionnaire is a survey instrument that assesses a variety of coping strategies that individuals may use in an attempt to deal with stress (Carver, 1997). Avoidant coping and adaptive coping are the two main coping styles that are evaluated by this survey. In the literature, avoidant coping may also be referred to as maladaptive coping, and adaptive coping may be referred to as approach coping. Two general coping styles that are also often discussed in the literature are problem-focused and emotion-focused coping. Problem-focused coping focuses on resolving a stressful situation and has been shown to be the most adaptive. Emotion-focused coping involves regulating emotional reactions to stress and may be either adaptive or avoidant depending on the specific actions taken by the individual in order to cope (Madhyastha et al., 2014). Greater use of avoidant coping has been shown to result in less favorable outcomes (Jalbrzikowski et al., 2012), while adaptive coping may lead to positive results such as more college retention (Madhyastha et al., 2014).

The PSS and Brief COPE instruments are often used in conjunction within research in order to link stress and coping mechanisms. Garber (2017) collected data from pharmacy 
students using the PSS-10, Brief COPE, and an open-ended question asking students about what coping methods they have discovered to be effective as a response to stress. Garber reports that this group of pharmacy students' perceived stress levels were found to be higher than average. The study notes that higher perceived stress levels are typically found in pharmacy students and in students generally. The pharmacy students in this study were found to use higher rates of adaptive coping mechanisms than avoidant coping mechanisms. One such example was the use of exercise, which was correlated with a lower PSS score. Another study at Pepperdine University explored connections between perceived stress, coping strategies, and health indicators (Furman et al., 2018). The PSS, Brief COPE, and the Pittsburgh Sleep Quality Index (PSQI) were administered to college students. This research confirmed the established trend of high perceived stress rates among students. Further, they found that avoidant coping strategies are correlated with higher perceived stress and lower sleep quality. There are many more examples of research that links perceived stress and coping strategies, especially among students who are shown to have higher rates of perceived stress (Brougham et al., 2009; Furman et al., 2018; Madhyastha et al., 2014; Pierceall \& Keim, 2007).

The stress that individuals experience and the coping mechanisms they practice are interrelated with many characteristics of that individual. Identifying factors such as gender impact how people see themselves and how they are seen by others. Gender has been shown to have a moderating effect on the relationship between stress and coping mechanisms in academic environments (Freire et al., 2018; Madhyastha et al., 2014). It has been shown that females often have significantly higher perceived stress levels than men. A study of US college students during the COVID-19 pandemic found higher PSS scores in women as well as trans and gender diverse students $(p<0.001)$ (Hoyt et al., 2021). The research on gender differences in utilization of 
coping mechanisms is mixed. Some studies have shown little to no gender differences in coping styles, such as was shown by Hamilton and Fagot in their study of undergraduate students (1988). The majority of evidence suggests greater use of adaptive and emotion-focused coping amongst women versus more frequent employment of avoidant and problem-focused coping in men (Brougham et al., 2009). Alternatively, a study by Matud (2004) found that women use more avoidant coping while men use more active coping styles. These differences may be explained by the varying types of stressful experiences encountered by women and men (Matud, 2004). Others have suggested there may be biological sex-based differences between male and female responses to stress. For example, women often utilize more social responses to stress, such as the "tend and befriend" approach. This has been suggested to be due to the more impactful effects of oxytocin on social behavior in females than in males (Taylor, 2006). The differences in coping mechanisms utilized by gender and sex need to be further studied with the recognition that the social aspects of gender and sex from a biological standpoint may have varying effects on coping differences.

In the discussion of perceived stress in 2020, it is critical to include the COVID-19 pandemic, an unprecedented stressor of global significance. This pandemic has been a major cause of stress, even for households or individuals without exposure to the virus, as a result of anxiety around the infectious disease, economic hardship, social isolation, and forced proximity to those in the same household (Bavel et al., 2020). According to a preliminary paper that looked at perceived stress in the world as a result of the COVID-19 pandemic, rates of anxiety and stress have increased due to the pandemic (Limcaoco et al., 2020). In addition to other relevant questions, this study used the PSS-10 to measure the perceived stress of participants from 41 different countries. Studies have also shown high perceived stress levels of students specifically 
throughout the COVID-19 pandemic. A study by AlAteeq et al. (2020) gathered demographic data, PSS-10 responses, and the emotions and concerns about the outbreak from students in the Kingdom of Saudi Arabia. The results showed that the students had moderate (55\% of students) to high (30.2\% of students) stress levels during the COVID-19 outbreak. The PSS-10 was also used by Son et al. (2020) in an interview survey study on the effect of COVID-19 on college student mental health in the United States. The results showed that $71 \%$ of student respondents reported increased stress and anxiety as a result of the COVID-19 outbreak. As this pandemic begins to wane, there is a looming increase in the world's already prevalent mental health crisis.

Coping mechanisms have been shown to be closely associated with perceived stress levels as explored above and throughout this paper. Like many previous studies, the current study is an evaluation of correlation rather than causation since either variable may be affecting the other. It has been established that college students have especially high rates of stress compared to the average population as measured by the PSS (Furman et al., 2018). Due to the increased stress caused by the COVID-19 pandemic, further inquiry regarding the relationship between perceived stress and coping mechanisms of a college community may result in new knowledge in this field. This study examines the impact of the additional stressor of the COVID19 pandemic on top of preexisting academic stress.

This thesis specifically explores the relationship between coping mechanisms utilized by Portland State University (PSU) community members and the perceived stress levels of the community amidst the COVID-19 pandemic. It also investigates whether gender has a moderating effect on this association. Finally, it assesses differences in perceived stress levels and coping mechanisms utilized between genders. 


\section{Methods}

A survey was distributed virtually to members of the PSU community in order to collect anonymous data on stress and coping mechanisms. Data were collected from 231 community members from October 2020 to December 2020. Participants consisted of PSU students, faculty/staff, and alumni. Due to COVID-19, most classes at the university were being conducted online. The survey was created using Google Forms and the link was sent to various PSU groups and classes. Informed consent was obtained from all participants prior to their completion of the survey.

Due to the presence of human research subjects in this research, the PSU Institutional Review Board (IRB) was consulted. The PSU IRB approved the use of all recruitment materials, consent procedures, survey instruments, and identifiable data collected from research participants.

The survey consisted of four distinct parts (see Appendix A). The first portion consisted of demographic questions that included relationship to the PSU community, age, gender, ethnicity, marital status, level of education, employment status, and household income.

The next 10 questions of the survey make up the Perceived Stress Scale (PSS-10) instrument (Cohen, 1994). The purpose of this psychological instrument is to measure one's perception of stress by inquiring as to how unpredictable, uncontrollable, and overloaded the participant finds their life to be (Cohen \& Williamson, 1988). These questions are answered using a 5-point Likert scale ranging from 0 (never) to 4 (very often) based on the respondent's feelings and emotions over the past month. For example, question six asks, "In the past month, how often have you found that you could not cope with all the things that you had to do?" The answers to the four positively worded questions were reversed for scoring. Resulting scores 
range from 0 to 40, with higher scores indicating higher perceived stress and vice versa. The PSS-10 has been shown to have adequate internal reliability and validity (Cohen \& Williamson, 1988). The PSS-10 has also more recently been shown to have reliability and validity in measuring the perceived stress of college students specifically (Roberti et al., 2006).

The Brief COPE was the next instrument utilized in the survey. It consists of 28 questions that assess the use of avoidant and adaptive coping mechanisms (Carver, 1997). Respondents were given options ranging from $1=\mathrm{I}$ haven't been doing this at all to $4=\mathrm{I}$ 've been doing this a lot as a response to stated coping habits. For example, one statement reads, "I've been concentrating my efforts on doing something about the situation I'm in." The avoidant and adaptive coping mechanisms were added separately for scoring. Subtypes of the avoidant coping style include self-distraction, denial, substance use, behavioral disengagement, venting, and selfblame. Categories of adaptive coping assessed in the questionnaire include active coping, seeking emotional support, use of informational support, positive reframing, planning, and acceptance (see Appendix B). The division of this instrument into these two major factors and the exclusion of religion and humor from the final scoring was based on the factor analysis done by Eisenberg et al. (2012). The Brief COPE has been shown to have adequate internal reliability (Carver, 1997).

The final two questions were open-ended and the first asks: "What strategies have you used to cope with stress in the past 6 months that have felt effective?" To give the participants context, coping strategies were defined as any behavioral or psychological methods that you engage in to deal with stressful events and examples were given. The answers to this question were hand-coded to determine the four most frequently reported strategy categories. The last question asks: "Do you feel that COVID-19 has increased your stress level?" The answers to this 
question were analyzed by separately adding the number of participants that said yes, the number of participants that said no, and the number of participants that said both yes and no.

The data collected from the survey were entered into the Statistical Package for the Social Sciences (SPSS) software version 27.0 and statistical analyses were performed. Descriptive statistics were run to determine the demographics of the study population as well as their average PSS and Brief COPE responses. Factor analyses were done to measure the internal reliability of the PSS-10 instrument, the set of Brief COPE questions regarding adaptive coping mechanisms, and the set of Brief COPE questions regarding avoidant coping mechanisms. A Pearson correlation was conducted to determine whether there was an association between PSS scores and adaptive coping mechanisms as measured by the Brief COPE. This test was also run to determine whether there was an association between PSS scores and avoidant coping mechanisms as measured by the Brief COPE. Stratified Pearson correlations were also performed by gender in order to explore whether gender had a moderating effect on the association between PSS and Brief COPE scores. An independent t-test was done to see if there was a difference in PSS score, Brief COPE adaptive score, or Brief COPE avoidant score means between genders. Although non-binary and transgender were given as options when participants were asked their gender, these participant responses were not included in the gendered analyses due to the limited amount of responses from this population. The differences were considered statistically significant when p-values were less than 0.05 . The open-ended questions were analyzed as described above. Finally, another independent t-test was run between the PSS scores of those that reported some form of exercise and those that did not in response to the open-ended question asking what strategies the participant has used to cope with stress in the past 6 months that have felt effective. 


\section{Results}

The demographic information collected from participants includes their relation to PSU, age, gender, ethnicity, marital status, highest degree or level of school completed, employment status, and household income. Table 1 describes the study sample. A total of 231 participants consented to and completed the survey online. Among the 231 PSU community members that completed the survey, $210(90.9 \%)$ were students and $17(7.4 \%)$ were faculty or staff. Of the respondents, $172(74.5 \%)$ were female and 59 (21.2\%) were male. Participants were asked their gender in order to be inclusive to all individuals who identify socially as a certain gender regardless of whether it matches their biological sex at birth. The convention of using female or male to describe gender was chosen for the purposes of this study, although we recognize the complexities of these labels (Pryzgoda, 2000). The majority of study participants identified as PSU students, age 18-24, female, white, single, having obtained a high school degree, employed, and having a household income of $\$ 10 \mathrm{k}-\$ 50 \mathrm{k}$. The perceived stress of the participants was measured using the PSS instrument which resulted in one score for every individual. The mean (SD) PSS of the sample was 21.77 (6.06). The median (Min, Max) PSS of the sample was 22.00 $(7,36)$. The types of coping mechanisms utilized by the participants were measured using the Brief COPE instrument which resulted in two scores for every individual, one which measures the use of adaptive coping mechanisms and the other which measures the use of avoidant coping mechanisms. The mean (SD) Brief COPE adaptive score of the sample was 34.07 (6.41). The median (Min, Max) Brief COPE adaptive score of the sample was $34.00(20,48)$. The mean (SD) Brief COPE avoidant score of the sample was 25.36 (5.28). The median (Min, Max) Brief COPE avoidant score of the sample was $25.00(15,41)$ (Table 1). 


\section{Table 1}

Study Participant Characteristics $(N=231)$

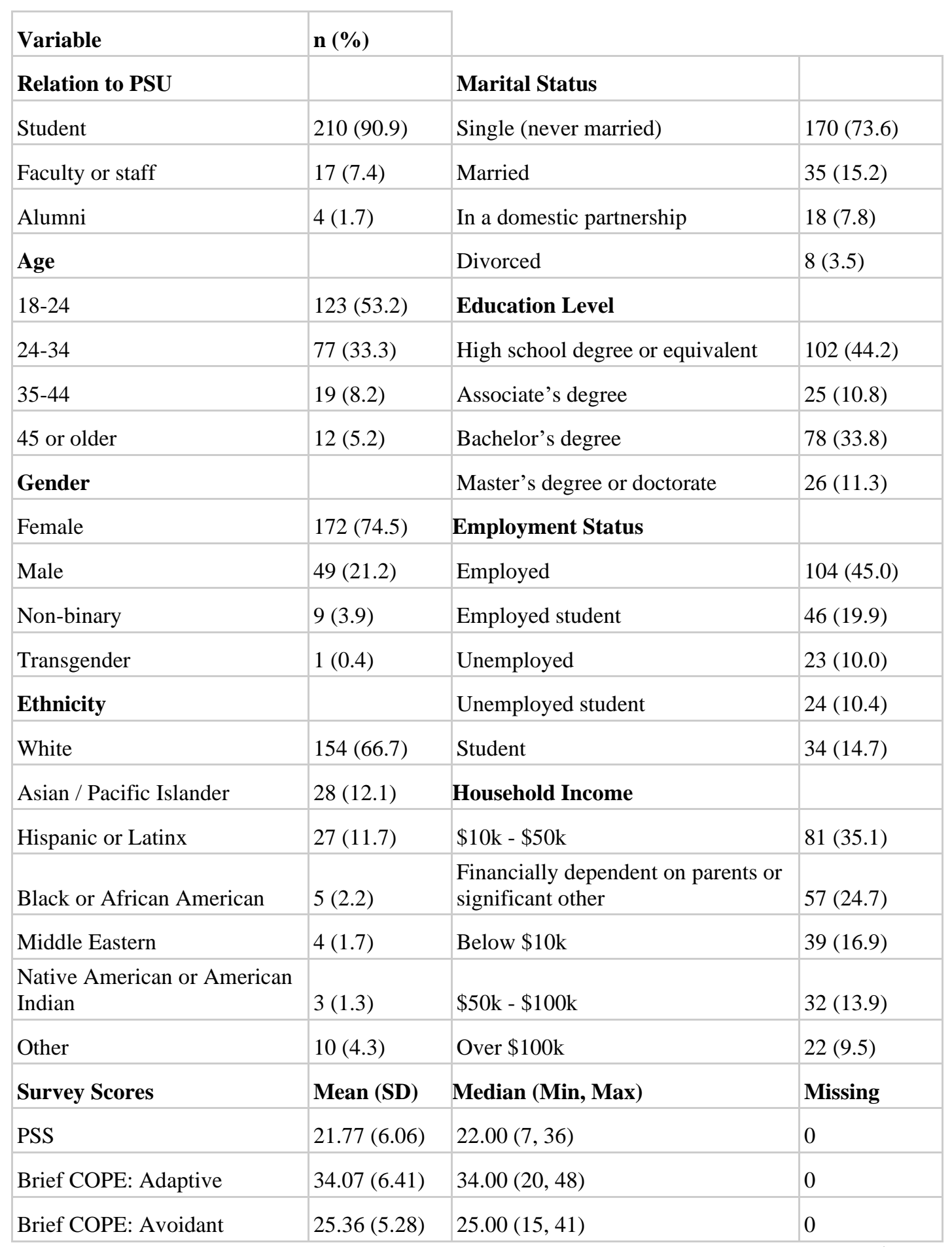

Note. PSS $=$ Perceived Stress Scale. COPE $=$ Coping Orientation to Problems Experienced. "Other" race category combines multiracial, North African, and Slavic. 
The PSS-10 instrument was shown to have adequate internal reliability with a Cronbach's alpha of $0.867(\alpha=0.867)$. The set of Brief COPE questions regarding adaptive coping mechanisms were shown to have adequate internal reliability with a Cronbach's alpha of 0.838 ( $\alpha=0.838$ ). The set of Brief COPE questions regarding avoidant coping mechanisms were shown to have adequate internal reliability with a Cronbach's alpha of $0.720(\alpha=0.720)$.

As displayed in Table 2, the PSS and adaptive Brief COPE scores of the full study sample were negatively correlated $(r=-0.149 ; p=0.023)$. The PSS and avoidant Brief COPE scores of the full study sample were shown to have a statistically significant positive correlation of $0.682(p<0.001)$. A significant correlation was not found between the adaptive and avoidant Brief COPE scores (Table 2).

\section{Table 2}

Pearson Correlation Coefficient Matrix of PSS With Brief COPE Scores Among the PSU Community $(N=231)$

\begin{tabular}{|l|l|l|l|}
\hline & PSS Total & Brief COPE: Adaptive & Brief COPE: Avoidant \\
\hline PSS Total & 1 & & \\
\hline Brief COPE: Adaptive & $-0.149^{*}$ & 1 & \\
\hline Brief COPE: Avoidant & $0.682^{* * *}$ & 0.017 & 1 \\
\hline
\end{tabular}

$* \mathrm{p}<0.05, * * \mathrm{p}<0.01, * * * \mathrm{p}<0.001$

Note. PSS $=$ Perceived Stress Scale. COPE $=$ Coping Orientation to Problems Experienced.

Table 3 shows the Pearson correlations stratified by gender. For both females and males, a positive correlation was found between PSS and avoidant Brief COPE scores $(r=0.657, r=$ 0.669; $p<0.001)$. No statistically significant correlations were found between PSS and adaptive coping or between the two coping styles for either gender. 


\section{Table 3}

Stratified Pearson Correlation Coefficient Matrix of PSS With Brief COPE Scores Among the PSU Community by Gender $(N=221)$

\begin{tabular}{|l|l|l|l|}
\hline Females (N=172) & PSS Total & Brief COPE: Adaptive & Brief COPE: Avoidant \\
\hline PSS Total & 1 & & \\
\hline Brief COPE: Adaptive & -0.13 & 1 & \\
\hline Brief COPE: Avoidant & $0.657 * * *$ & 0.042 & 1 \\
\hline Males (N=49) & & & \\
\hline PSS Total & 1 & & \\
\hline Brief COPE: Adaptive & -0.123 & 1 & 1 \\
\hline Brief COPE: Avoidant & $0.669 * * *$ & 0.087 & \\
\hline
\end{tabular}

Note. $* \mathrm{p}<0.05, * * \mathrm{p}<0.01, * * * \mathrm{p}<0.001$

Note. PSS $=$ Perceived Stress Scale. COPE $=$ Coping Orientation to Problems Experienced. The 10 nonbinary/transgender respondents were not included in this analysis.

PSS and Brief COPE score means were compared by gender as shown in Table 4. The mean (SD) PSS score for females was 22.34 (5.68). The mean (SD) PSS score for males was

18.57 (6.01). The difference in means between the two genders was 3.77 , which was statistically significant $(t=4.05, p<0.001)$. Mean scores on the Brief COPE were not shown to be significantly different between genders (Table 4).

\section{Table 4}

Independent T-Tests Comparing Female and Male PSS and Brief COPE Scores $(N=221)$

\begin{tabular}{|l|r|r|r|}
\hline Gender Comparison & Females (N=172) Mean (SD) & Males (N=49) Mean (SD) & t-statistic (df) \\
\hline PSS Total & $22.34(5.68)$ & $18.57(6.01)$ & $4.05 * * *(219)$ \\
\hline Brief COPE: Adaptive & $34.01(6.51)$ & $34.55(6.32)$ & $-0.52(219)$ \\
\hline Brief COPE: Avoidant & $25.39(4.98)$ & $24.29(5.50)$ & $1.34(219)$ \\
\hline$* \mathrm{p}<0.05, * * \mathrm{p}<0.01, * * * \mathrm{p}<0.001$ & & & \\
\hline
\end{tabular}

Note. PSS $=$ Perceived Stress Scale. COPE $=$ Coping Orientation to Problems Experienced. $\mathrm{SD}=$ standard deviation. $\mathrm{df}=$ degrees of freedom. Equal variances assumed. The 10 non-binary/transgender respondents were not included in this analysis. 
The first open-ended question asks: "What strategies have you used to cope with stress in the past 6 months that have felt effective?" The answers to this question were hand-coded to find the four most common response categories. Starting from most common these were found to be: various forms of physical activity which was often combined with being outside, seeking social support or connection, mindfulness practices (including breathing exercises, yoga, and meditation), and disclosure in the form of journaling or seeing a therapist. The second openended question asks: "Do you feel that COVID-19 has increased your stress level?" In response, $205(88.7 \%)$ participants indicated yes, $10(4.3 \%)$ participants indicated no, and $10(4.3 \%)$ participants reported a combination of yes and no. There were $6(2.6 \%)$ responses that were unclear and therefore, not grouped into one of these three categories.

In response to the first open-ended question, 142 (61.5\%) respondents reported exercise as part of their response. An independent t-test was used to compare the PSS score of those who included exercise in their answer to this question versus those who did not. The mean (SD) PSS score for those who reported exercise as effective in coping with stress was 21.17 (5.88), while the mean (SD) PSS score for those who did not report exercise was 22.74 (6.25). The difference in means between these two groups was 1.57 , which approached statistical significance $(p=$ $0.055)$.

\section{Discussion}

The primary purpose of this study was to examine the relationship between perceived stress and coping mechanisms of the PSU community amidst the COVID-19 pandemic. In addition, this research assessed whether there was a moderating effect of gender on the relationship between perceived stress and coping mechanisms in this population. Differences in perceived stress levels and coping mechanisms utilized between genders were also evaluated. 
Higher perceived stress levels were reported by participants of this study $(M=21.77, S D$ $=6.06)$ as compared to normative values for undergraduate college students $(M=18.15, S D=$ 6.92) (Roberti et al., 2006). This was not unexpected due to the rising stress of college students (Roberti et al., 2006) and the increased global stress levels as a result of the pandemic (Limcaoco et al., 2020). This finding is in agreement with previous literature and expands on the more current findings on the impact of the COVID-19 pandemic on student wellbeing.

Greater use of adaptive coping mechanisms compared to avoidant coping mechanisms were reported by the study participants. This finding is in agreement with prior research conducted by Garber which showed utilization of more adaptive coping than avoidant coping in pharmacy students. The Brief COPE mean scores calculated in this study were found to be similar to that of research collected from 140 US undergraduate students by Furman et al. (2018). This previous study reported an adaptive coping mean (SD) score of 39.6 (6.9) and a maladaptive (avoidant) coping mean (SD) score of 27.9 (5.5) as compared to the current study finding of 34.07 (6.51) and 25.36 (5.28) respectively. It is of note that Furman et al. included religion in their adaptive coping total score and humor in their maladaptive (avoidant) coping total score. Research on whether to classify humor and religion as adaptive or avoidant has been varied. It has been shown that humor may be categorized as either adaptive or avoidant (Furman et al., 2018). Eisenberg et al. (2012) determined that humor and religion were ambiguous as they were able to fit into either the adaptive or avoidant coping category when a factor analysis was conducted. Therefore, neither religion nor humor were included in either coping score in the current study. The findings of the current study further support the established pattern of greater student use of adaptive compared to avoidant coping mechanisms. This pattern may be beneficial to students as adaptive coping mechanisms have shown more positive outcomes (Jalbrzikowski 
et al., 2012).

The results of this study indicated a positive association between the use of avoidant coping mechanisms and perceived stress levels. This finding is supported by previous research done using a sample of college students (Furman et al., 2018). The use of adaptive coping mechanisms and perceived stress levels were found to be negatively correlated. This is contrary to Furman et al. (2018) who did not find a significant correlation between adaptive coping and perceived stress. These findings indicate a positive correlation between the avoidant coping and perceived stress variables as well as a negative correlation between the adaptive coping and perceived stress variables. Although these relationships do not imply causality, they indicate potential points of intervention that may impact the established system. This potential is explored in the paragraphs to follow.

There are two avenues to be explored in analyzing the positive relationship between utilization of avoidant coping mechanisms and perceived stress levels. It may be that higher levels of perceived stress of the participants leads them to use more avoidant coping. For example, self-distraction by watching television may be used often by students who are more stressed as a result of their schooling and wanting to forget about all of the school work they have to do. Another possibility is that the study participants' use of avoidant coping mechanisms is leading to their greater feelings of stress. If the students use of self-distraction by watching television is leading to procrastination of assignments and subsequent worry about missing deadlines and getting behind in class, this may increase their stress levels.

Similarly, a couple viewpoints may be used to look at the negative association between adaptive coping utilization and perceived stress levels. It is possible that lower perceived levels of stress steers the use of adaptive coping amongst the participants. For instance, if an individual 
is less stressed, they may feel that they have more time and mental capacity to seek out emotional support. Alternatively, it could be that higher use of adaptive coping is influencing the participants to have lower stress levels. This can be exemplified by students that use a calendar or task list to plan out their days and assignments. These students might have lower stress levels due to their organizational skills.

Regardless of the directionality of these two relationships, the findings of this study show that the two variables of stress and coping change together. Because management of stress and new strategies of coping can be learned, this provides an opportunity to intervene in order to increase quality of life and wellbeing. Below we explore intervention strategies that are supported by the literature.

Stress management interventions such as mindfulness-based stress reduction (MBSR) and mind-body skills groups (MBSG) are commonly implemented to aide people in lowering stress and improving coping skills. The goal of such programs is to decrease stress by teaching participants to use adaptive coping mechanisms, such as meditation and breath work, and modifying their perceptions around stress by increasing awareness of thoughts and feelings in the present moment. MBSR has been shown to significantly reduce stress as measured by the PSS pre- and post-intervention (Holzel et al., 2010). Holzel et al. also found that this decrease in stress correlated with decreased gray matter density in the amygdala, a crucial part of the brain that modulates the stress response by recognizing stressful stimuli and instigating adaptive coping as a result. Similarly, decreased stress levels and increased resilience and optimism are a couple of the positive results shown amongst medical students, a high stress population, that participate in MBSG (Gordon, 2014).

Mindfulness-based movement (MBM) is a program similar to MBSR, though it focuses 
more closely on movement as the modality to cultivate awareness. MBM primarily uses yoga to prepare the mind and body for other mindfulness practices such as seated meditation, body scanning, and breathing exercises (Robert-McComb et al., 2015). In a study by Robert-McComb et al., MBM was shown to decrease anxiety, lower perceived stress, increase an adaptive coping technique called reflective coping, and increase wellbeing in a sample of female college students. Yoga alone has also been shown to have a positive impact on stress. Though more research is needed, a review of yoga programs by Yang (2007) proposed that yoga practice may be effective in reducing risk factors for chronic disease. This may be a result of yoga inducing psychological changes such as lowering stress levels and improving mood. A theory proposed by Streeter et al. (2012) suggests that yoga helps to reduce stress and its related disorders by increasing parasympathetic nervous system (PNS) and gamma amino-butyric acid (GABA) activity.

Physical activity is another strategy that has shown to be effective in reducing stress. A systematic review by Chan et al. (2019) assessed the benefits of physical activity on mood. The paper suggests that 10 to 30 minutes of anaerobic exercise can decrease stress and enhance mood. Chen et al. (2017) proposed that the mechanism for this may involve the elevation of glucocorticoid cortisol which increases dopamine in the medial prefrontal cortex. This activation is crucial in the initiation of active coping.

As documented in these studies and others, the aforementioned interventions may act as adaptive mechanisms that aid in decreasing stress. Therefore, we suggest mind-body and physical activity practices as a possible avenue to lowering stress levels. Though they generally have positive results, it is important to recognize that any of these strategies may be used in an avoidant manner by individuals.

The gender stratified correlation results show a positive relationship between the 
utilization of avoidant coping mechanisms and perceived stress levels for members of both male and female genders. This finding is similar to that of the full sample correlation, indicating little to no difference in this correlation between genders. A significant correlation between adaptive coping and perceived stress was not found for either gender. Though the negative relationship between adaptive coping and stress was found to by significant amongst the full study sample ( $p$ $<0.05)$, this relationship was not found to be significant in the female or male respondents. This is likely due to the smaller sample size of both genders compared to the combined study population. These findings suggest that, in this study population, gender was not a moderator in the relationship between perceived stress and coping. This is contradictory to the findings in the literature that show gender to have a moderating effect on this relationship. Studies by Freire et al. (2018) and Madhyastha et al. (2014) both indicate that gender plays a large moderating role between the stress and coping association. Freire et al. suggested that at lower perceived levels of stress, both males and females use more adaptive coping. With increased perception of stress though, males tend to use more adaptive coping mechanisms than females. This relationship needs to be further studied in order to better understand how gender affects the association between stress and coping. It will also be necessary to understand this association in people who are non-binary or non-gendered.

Female study participants reported higher perceived stress levels than their male counterparts as shown by our analysis of reported PSS responses. This agrees with the general consensus in the literature that females experience more stress than males (Hoyt et al., 2021; Matud, 2004; Pierceall \& Keim, 2007). Hoyt et al. found significantly higher levels of perceived stress and anxiety among women and trans and gender diverse students than men during the COVID-19 pandemic. The current study did not observe a significant difference between 
genders in adaptive or avoidant coping styles as measured by the Brief COPE. This opposes the abundance of research that shows women use more adaptive and emotion-focused coping than men (Brougham et al., 2009; Madhyastha et al., 2014). However, it has been suggested that differences in coping styles between genders have been decreasing recently as social gender constraints have been shifting (Matud, 2004). Further research is needed to delineate the differences in coping between genders. Separating the social and biological effects of gender and sex, respectively, on coping may help researchers to understand the seemingly convoluted relationship.

While female participants were found to have higher perceived stress, they did not report using more avoidant coping mechanisms. This is contrary to what may have been expected considering the strong positive correlation observed between stress and avoidant coping. It is beyond the scope of the data collected in this study to explain why females reported experiencing higher stress. Undoubtedly, there are other variables affecting perceived stress besides the style of coping used by the individual, such as trauma, discrimination, financial difficulties, and chronic illness. Further investigation regarding these other variables should be done within this population in order to better understand why females are experiencing higher stress levels than males but are not reporting greater use of avoidant coping.

The current study found that physical activity (particularly outside), social support or connection, mindfulness practices, and disclosure were coping mechanisms that participants perceived to be effective for them in the past six months. These coping mechanisms are generally seen as adaptive. That said, it is also possible for these strategies to be used in an avoidant manner. Garber asked the pharmacy students in his study a similar open-ended question that reads, "What have you found to be an effective way to cope with stress?" (p. 3). Similar to our 
study's findings, the two most common themes reported in response were physical exercise and socializing/talking to others. Garber added exercise as a coping mechanism to the Brief COPE instrument for his study. In his analysis, he found a statistically significant correlation between lower perceived stress and respondents that noted using exercise as a coping mechanism. This is analogous to the finding in the current study that found a difference of 1.57 between the PSS score means of participants that reported exercise as an effective coping mechanism compared to those that did not, which approached statistical significance $(p=0.055)$. The lower PSS score mean was found among the group that reported using exercise as a coping mechanism, suggesting that exercise may actually correlate with reduced perceived stress in the study population. This analysis was peripheral to the study's research question and exercise was not specifically asked about in this open-ended question, so this relationship cannot be explained further here. In asking community college students how they cope with stress, Pierceall and Keim (2007) found talking to family and friends, leisure activities, and exercise to be the top three most reported responses. The authors did not conduct any statistical analyses to compare these responses to stress levels, but they concluded that these coping mechanisms are healthy and that therefore, most of the students that participated in their study used healthy coping mechanisms.

Our study also found that $88.7 \%$ of participants suggested that their stress level had increased as a result of the COVID-19 pandemic. A study of medical students in Saudi Arabia towards the beginning of the pandemic found a moderate to high level of stress amongst their participants (AlAteeq et al., 2020). Answers to a qualitative question regarding emotions and concerns surrounding the outbreak revealed participant feelings of depression, stress, anxiety, fear, anger, and being unmotivated. AlAteeq et al. suggested that these responses may be due in 
part to the challenges of social distancing and distance learning. Although the reasons for the increased stress reported by the participants in our study were not further explored, it is clear that they viewed the pandemic as a contributor to their stress level, as did participants in other studies conducted during the COVID-19 outbreak.

While this study contributes knowledge regarding the perceived stress and coping mechanisms utilized by members of the PSU community during the pandemic, it does have limitations. One important limitation is its lack of generalizability. The findings cannot speak for the entire PSU community because the majority of respondents were white, younger, female, employed students with a household income of $\$ 10 \mathrm{k}-\$ 50 \mathrm{k}$. PSU is a highly diverse campus and represents much more than this specific demographic. Another limitation is that many of the studies cited in this paper were conducted solely with student participants. Though the majority of participants were students, the current study also included faculty, staff, and alumni. These participants may have generally differing perceived stress levels and use of coping mechanisms and therefore, the findings may be less cohesive. The use of subjective self-report questionnaires may also be a limitation of this study. It is possible that participants did not answer the questions with complete accuracy due to social desirability bias or a lack of introspective ability.

Further areas of study were uncovered as a result of this research. A closer look into the coping mechanisms endorsed by the study population could allow for more specific recommendations that may help individuals within the community decrease their stress level. This could be done using statistical analysis to determine whether participants that reported using certain adaptive coping mechanisms actually had lower perceived stress, as was done with physical activity in this study. This could also be explored by incorporating questions regarding specific coping mechanisms into the Brief COPE instrument as was done by Garber (2017). 
Future research should also explore the differences in perceived stress and coping mechanisms utilized by ethnicity and socioeconomic class of this community. Data from a broader diversity of study participants needs to be collected in order to do so. Finally, the impact of gender on perceived stress and coping should be further explored using a larger sample size. This may help to clarify the confusion around what effect gender has on these variables.

\section{Conclusion}

This study provides new knowledge regarding perceived stress and coping mechanisms utilized by the PSU community during the COVID-19 pandemic. The effect of gender on the relationship between stress and coping was explored along with any differences within these variables based on gender. The study population had high perceived stress levels and used more adaptive than avoidant coping mechanisms. A significant positive correlation was found between the use of avoidant coping and perceived stress level, while adaptive coping and perceived stress correlated negatively. Gender did not have a moderating effect on the relationship between stress and coping, though female participants reported higher levels of perceived stress than males. Physical activity, often outdoors, was the most commonly reported coping mechanism that was perceived as effective by the study respondents. The majority of respondents indicated they were more stressed due to the pandemic. We explored and suggested mind-body and physical activity practices as adaptive coping strategies to help with lowering stress levels. Especially considering the effects of the COVID-19 pandemic on our society's mental health, these practices should be implemented and encouraged on college campuses.

\section{Acknowledgements}

The authors would like to gratefully acknowledge Eli Michaels MPH, Ph.D candidate for her assistance in data analysis. 


\section{References}

AlAteeq, D. A., Aljhani, S., \& AlEesa, D. (2020). Perceived stress among students in virtual classrooms during the COVID-19 outbreak in KSA. Journal of Taibah University Medical Sciences, 15(5), 398-403. https://doi.org/10.1016/j.jtumed.2020.07.004

American Psychological Association (2020). APA Dictionary of Psychology. Dictionary APA. https://dictionary.apa.org/coping-behavior

Bavel, J. J. V., Baicker K., Boggio P. S., Capraro V., Cichocka, A., Cikara M., Crokett M. J., Crum, A. J., Douglas, K. M., Druckman, J. N., Drury, J., Dube, O., Ellemers, N., Finkel, E. J., Fowler, J. H., Gelfand, M., Han, S., Haslam, S. A., Jetten, J., Kitayama, S, et al. (2020). Using social and behavioural science to support COVID-19 pandemic response. Nature Human Behaviour, 4, 460-471. https://doi.org/10.1038/s41562-020-0884-Z

Brougham, R. R., Zail, C. M., Mendoza, C. M., \& Miller, J. R. (2009). Stress, sex differences, and coping strategies among college students. Current Psychology, 28, 85-97. https://doi.org/10.1007/s12144-009-9047-0

Carver, C. S. (1997). You want to measure coping but your protocol's too long: Consider the Brief COPE. International Journal of Behavioral Medicine, 4(1), 92-100. 10.1207/s15327558ijbm0401_6

Centers for Disease Control and Prevention. (2018, October 31). Well-Being Concepts. CDC. https://www.cdc.gov/hrqol/wellbeing.htm

Chan, J. S. Y., Liu, G., Liang, D., Deng, K., Wu, J., \& Yan, J. H. (2019). Special issue Therapeutic benefits of physical activity for mood: A systematic review on the effects of exercise intensity, duration, and mobility. The Journal of Psychology, 153(1), 102-125. https://doi.org/10.1080/00223980.2018.1470487

Chen, C., Nakagawa, S., An, Y., Ito, K., Kitaichi, Y., \& Kusumi, I. (2017). The exerciseglucocorticoid paradox: How exercise is beneficial to cognition, mood, and the brain while increasing glucocorticoid levels. Frontiers in Neuroendocrinology, 44, 83-102. https://doi.org/10.1016/j.yfrne.2016.12.001

Cohen, S. (1994). Perceived Stress Scale. Mind Garden. http://www.mindgarden.com/documents/PerceivedStressScale.pdf

Cohen, S., Kamarck, T., \& Mermelstein, R. (1983). A global measure of perceived stress. Journal of Health and Social Behavior, 24(4), 385-396. https://www.jstor.org/stable/2136404

Cohen, S., \& Williamson, G. (1988). Perceived stress in a probability sample of the United States. In S. Spacapan \& S. Oskamp (Eds.), The Claremont Symposium on applied social psychology: The social psychology of health (pp. 31-67). Sage Publications, Inc. 
Eisenberg, S. A., Shen, B., Schwarz E. R., \& Mallon, S. (2012). Avoidant coping moderates the association between anxiety and patient-related physical functioning in heart failure patients. Journal of Behavioral Medicine, 35(3), 253-261. 10.1007/s10865-011-9358-0

Farrell, A. K. \& Simpson J. A. (2017). Effects of relationship functioning on the biological experience of stress and physical health. Elsevier, 13, 49-53. https://doi.org/10.1016/j.copsyc.2016.04.014

Freire, C., Ferradas, M., Nunez, J. S., Valle, A., \& Vallejo, G. (2018). Eudaimonic well-being and coping with stress in university students: The mediating/moderating role of selfefficacy. International Journal of Environmental Research and Public Health, 16(1), 48. $\underline{10.3390 / i j e r p h 16010048}$

Furman, M., Joseph, N., \& Miller-Perrin, C. (2018). Associations between coping strategies, perceived stress, and health indicators. Psi Chi Journal of Psychological Research, 23(1), 61-72. https://doi.org/10.24839/2325-7342.JN23.1.61

Garber, M. C. (2017). Exercise as a stress coping mechanism in a pharmacy student population. American Journal of Pharmaceutical Education, 81(3), article 50. 10.5688/ajpe 81350

Gordon, J. S. (2014). Mind-body skills groups for medical students: Reducing stress, enhancing commitment, and promoting patient-centered care. BMC Medical Education, 14, article 198. https://doi.org/10.1186/1472-6920-14-198

Gustems-Carnicer, J., Calderon, C., Batalla-Flores, A., \& Esteban-Bara, F. (2018). Role of coping responses in the relationship between perceived stress and psychological wellbeing in a sample of Spanish educational teacher students. Psychological Reports, 122(2), 380-397. 10.1177/0033294118758904

Hamaideh, S. H., Al-Omari, H., \& Al-Modallal, H. (2016). Nursing students' perceived stress and coping behaviors in clinical training in Saudi Arabia. Journal of Mental Health, 26(3), 197-203. https://doi.org/10.3109/09638237.2016.1139067

Hamilton, S., \& Fagot, B.I. (1988). Chronic stress and coping styles: A comparison of male and female undergraduates. Journal of Personality and Social Psychology, 55(5), 819-23. https://doi.org/10.1037//0022-3514.55.5.819

Holzel, B. K., Carmody, J., Evans, K. C., Hoge, E. A., Dusek, J. A., Morgan, L., Pitman, R. K., \& Lazar, S. W. (2010). Stress reduction correlates with structural changes in the amygdala. Social Cognitive and Affective Neuroscience, 5(1), 11-17. https://doi.org/10.1093/scan/nsp034 
Hoyt, L. T., Cohen, A. K., Dull, B., Castro, E. M., \& Yazdani, N. (2021). “Constant stress has become the new normal": Stress and anxiety inequalities among U.S. college students in the time of COVID-19. Journal of Adolescent Health, 68(2), 270-276. https://doi.org/10.1016/j.jadohealth.2020.10.030

Jalbrzikowski, M., Sugar, C. A., Zinberg, J., Bachman, P., Cannon, T. D., \& Bearden, C. E. (2012). Coping styles of individuals at clinical high risk for developing psychosis. Early Intervention in Psychiatry, 8(1), 68-76. https://doi.org/10.1111/eip.12005

Lazarus, R. S., \& Folkman, S. (1984). Stress, Appraisal, and Coping. Spring Publishing Company, Inc.

Limcaoco, R. S. G., Mateos, E. M., Fernandez, J. M., \& Roncero, C. (2020). Anxiety, worry and perceived stress in the world due to the COVID-19 pandemic, March 2020. Preliminary results. https://doi.org/10.1101/2020.04.03.20043992

Madhyastha, S., Latha, K. S., \& Kamath, A. (2014). Stress, coping and gender differences in third year medical students. Journal of Health Management, 16(2), 315-326. https://doi.org/10.1177/0972063414526124

Matud, M. P. (2004). Gender differences in stress and coping styles. Personality and Individual Differences, 37(7), 1401-1415. https://doi.org/10.1016/j.paid.2004.01.010

Padgett, D. A., \& Glaser R. (2003). How stress influences the immune response. Trends in Immunology, 24(8), 444-448. https://doi.org/10.1016/S1471-4906(03)00173-X

Pierceall, E. A., \& Keim, M. C. (2007). Stress and coping strategies among community college students. Community College Journal of Research and Practice, 31(9), 703-712. https://doi.org/10.1080/10668920600866579

Pryzgoda, J., \& Chrisler, J. C. (2000). Definitions of gender and sex: The subtleties of meaning. Sex Roles, 43(7/8), 553-569. https://doi.org/10.1023/A:1007123617636

Roberti, J. W., Harrington, L. N., Storch, E. A. (2006). Further psychometric support for the 10item version of the perceived stress scale. Journal of College Counseling, 9(2), 135-147. https://doi.org/10.1002/j.2161-1882.2006.tb00100.x

Robert-McComb, J. J., Cisneros, A., Tacon, A., Panike, R., Norman, R., Qian, X, \& McGlone, J. (2015). The effects of Mindfulness-Based Movement on parameters of stress. International Journal of Yoga Therapy, 25(1), 79-88. https://doi.org/10.17761/1531-2054-25.1.79

Sapolsky, R. M. (1994). Why zebras don't get ulcers: A guide to stress, stress related diseases, and coping. W.H. Freeman. 
Son, C., Hedge, S., Smith, A., Wang, X., \& Sasangohar, F. (2020). Effects of COVID-19 on college students' mental health in the United States: Interview survey study. Journal of Medical Internet Research, 22(9), e21279. 10.2196/21279

Streeter, C. C., Gerbarg, P. L., Saper, R. B., Ciraulo, D. A., \& Brown, R. P. (2012). Effects of yoga on the autonomic nervous system, gamma-aminobutyric-acid, and allostasis in epilepsy, depression, and post-traumatic stress disorder. Medical Hypotheses, 78(5), 571579. https://doi.org/10.1016/j.mehy.2012.01.021

Taylor, S. E. (2006). Tend and befriend: Biobehavioral bases of affiliation under stress. Current Directions in Psychological Science, 15(6), 273-277. https://doi.org/10.1111\%2Fj.1467-8721.2006.00451.x

Yang, K. (2007). A review of yoga programs for four leading risk factors of chronic diseases. Evidence-Based Complementary and Alternative Medicine, 4(4), 487-491. https://dx.doi.org/10.1093\%2Fecam\%2Fnem154 


\section{Appendix A}

The following survey was presented to the study participants:

\section{Consent and demographic questions}

1. I have had the chance to read and think about the information in this form. I have asked any questions I have, and I can make a decision about my participation. I understand that I can ask additional questions anytime while I take part in the research. LINK TO CONSENT FORM: https://1drv.ms/w/s!Aq7-jDlUvRn-gUb2hpOjHKNK-

\section{L_Y? $=$ rTnmRz}

- I agree to take part in this study

- I do not agree to take part in this study (please do not continue the survey in this case)

2. What is your relation to the Portland State University community?

- Student

- Faculty or staff

- Alumni

- Other:

3. What is your age?

- Under 18

- 18-24 years old

- 25-34 years old

- 35-44 years old

- 45-54 years old

- Over 55

4. What is your gender?

- Male

- Female

- Non-binary

- Prefer not to say

- Other:

5. What is your ethnicity?

- White

- Hispanic or Latinx

- Black or African American

- Native American or American Indian

- Asian / Pacific Islander

- Other:

6. What is your marital status?

- Single (never married)

- Married

- In a domestic partnership

- Divorced

- Widowed 
7. What is the highest degree or level of school that you have completed?

- Less than a high school diploma

- High school degree or equivalent

- Bachelor's degree

- Master's degree

- Doctorate

- Other:

8. What is your current employment status?

- Employed full-time (40+ hours a week)

- Employed part-time (less than 40 hours a week)

- Unemployed (currently looking for work)

- Unemployed (not currently looking for work)

- Student

- Other:

9. What is your household income?

- Below \$10k

- $\$ 10 \mathrm{k}-\$ 50 \mathrm{k}$

- $\$ 50-\$ 100 \mathrm{k}$

- Over $\$ 100 \mathrm{k}$

- Financially dependent on parents or significant other

\section{Perceived Stress Scale}

0 - Never

1 - Almost never

2 - Sometimes

3 - Fairly often

4 - Very often

1. In the last month, how often have you been upset because of something that happened unexpectedly?

2. In the last month, how often have you felt that you were unable to control the important things in your life?

3. In the last month, how often have you felt nervous and "stressed"?

4. In the last month, how often have you felt confident about your ability to handle your personal problems?

5. In the last month, how often have you felt that things are going your way?

6. In the last month, how often have you found that you could not cope with all the things that you had to do?

7. In the last month, how often have you been able to control irritations in your life?

8. In the last month, how often have you felt that you were on top of things?

9. In the last month, how often have you been angered because of things that were outside of your control?

10. In the last month, how often have you felt difficulties were piling up so high that you could not overcome them? 


\section{Brief COPE}

1 - I haven't been doing this at all

$2-$ I've been doing this a little bit

3 - I've been doing a medium amount

$4-$ I've been doing this a lot

1. I've been turning to work or other activities to take my mind off things.

2. I've been concentrating my efforts on doing something about the situation I'm in.

3. I've been saying to myself "this isn't real.".

4. I've been using alcohol or other drugs to make myself feel better.

5. I've been getting emotional support from others.

6. I've been giving up trying to deal with it.

7. I've been taking action to try to make the situation better.

8. I've been refusing to believe that it has happened.

9. I've been saying things to let my unpleasant feelings escape.

10. I've been getting help and advice from other people.

11. I've been using alcohol or other drugs to help me get through it.

12. I've been trying to see it in a different light, to make it seem more positive.

13. I've been criticizing myself.

14. I've been trying to come up with a strategy about what to do.

15. I've been getting comfort and understanding from someone.

16. I've been giving up the attempt to cope.

17. I've been looking for something good in what is happening.

18. I've been making jokes about it.

19. I've been doing something to think about it less, such as going to movies, watching TV, reading, daydreaming, sleeping, or shopping.

20. I've been accepting the reality of the fact that it has happened.

21 . I've been expressing my negative feelings.

22. I've been trying to find comfort in my religion or spiritual beliefs.

23. I've been trying to get advice or help from other people about what to do.

24. I've been learning to live with it.

25. I've been thinking hard about what steps to take.

26. I've been blaming myself for things that happened.

27 . I've been praying or meditating.

28. I've been making fun of the situation.

\section{Open-ended questions}

1. What strategies have you used to cope with stress in the past 6 months that have felt effective? NOTE: Coping strategies are defined as any behavioral or psychological methods that you engage in to deal with stressful events. Examples include but are not limited to meditation, breathing techniques, journaling, time-management, seeking support from others, self-care, physical activity (specify what type).

2. Do you feel that COVID-19 has increased your stress level? 


\section{Resources}

Due to the mental or emotional discomfort that these questions may bring up, please reference the resources listed below if needed.

- Multnomah County Mental Health Call Center (24/7 crisis counseling by phone, with interpretation services for non-English speakers): 503-988-4888 or 800-7169769 (toll-free) or 711 (hearing-impaired)

- Portland State University Student Health and Counseling (SHAC) counseling services: 503-725-2800

- Headspace offers free online meditations

- BetterHelp Online Counseling: betterhelp.com

- neolth offers personalized stress management: neolth.com 


\section{Appendix B}

\section{Table B1}

Coping mechanisms assessed by the Brief COPE

\begin{tabular}{|l|l|}
\hline Coping Style Category & Specific Coping Mechanism \\
\hline Adaptive & Active Coping \\
\hline & Seeking Emotional Support \\
\hline & Use of Informational Support \\
\hline & Positive Reframing \\
\hline & Planning \\
\hline Avoidant & Acceptance \\
\hline & Self-Distraction \\
\hline & Denial \\
\hline & Substance Use \\
\hline & Behavioral Disengagement \\
\hline & Venting \\
\hline Uncategorized & Self-Blame \\
\hline & Religion \\
\hline & Humor \\
\hline
\end{tabular}

Note . $\mathrm{COPE}=$ Coping Orientation to Problems Experienced. 